\title{
Assessment of Cellular Proliferation in Tumors by PET Using ${ }^{18}$ F-ISO-1
}

\author{
Farrokh Dehdashti ${ }^{1,2}$, Richard Laforest ${ }^{1,2}$, Feng Gao ${ }^{2,3}$, Kooresh I. Shoghi ${ }^{1,2}$, Rebecca L. Aft ${ }^{2,4}$, Brian Nussenbaum ${ }^{2,4}$, \\ Friederike H. Kreisel ${ }^{2,5}$, Nancy L. Bartlett ${ }^{2,6}$, Amanda Cashen ${ }^{2,6}$, Nina Wagner-Johnson ${ }^{2,6}$, and Robert H. Mach ${ }^{1,2}$ \\ ${ }^{I}$ Divisions of Nuclear Medicine and Radiological Sciences, Edward Mallinckrodt Institute of Radiology, Washington University \\ School of Medicine, St. Louis, Missouri; ${ }^{2}$ The Alvin J. Siteman Cancer Center, Washington University School of Medicine, St. Louis, \\ Missouri; ${ }^{3}$ Division of Biostatistics, Washington University School of Medicine, St. Louis, Missouri; ${ }^{4}$ Department of Surgery, \\ Washington University School of Medicine, St. Louis, Missouri; ${ }^{5}$ Department of Pathology, Washington University School of \\ Medicine, St. Louis, Missouri; and ${ }^{6}$ Department of Medicine, Washington University School of Medicine, St. Louis, Missouri
}

This first study in humans was designed to evaluate the safety and dosimetry of a cellular proliferative marker, $\mathrm{N}$-(4-(6,7dimethoxy-3,4-dihydroisoquinolin-2(1H)-yl)butyl)-2-(2-18 F-fluoroethoxy)-5-methylbenzamide ( $\left.{ }^{18} \mathrm{~F}-\mathrm{ISO}-1\right)$, and evaluate the feasibility of imaging tumor proliferation by PET in patients with newly diagnosed malignant neoplasms. Methods: Patients with biopsy-proven lymphoma, breast cancer, or head and neck cancer underwent ${ }^{18} \mathrm{~F}$-ISO-1 PET. Tumor ${ }^{18} \mathrm{~F}-$ ISO-1 uptake was assessed semiquantitatively by maximum standardized uptake value, ratios of tumor to normal tissue and tumor to muscle, and relative distribution volume ratio. The PET results were correlated with tumor $\mathrm{Ki}-67$ and mitotic index, from in vitro assays of the tumor tissue. The biodistribution of ${ }^{18} \mathrm{~F}-\mathrm{ISO}-1$ and human dosimetry were evaluated. Results: Thirty patients with primary breast cancer $(n=13)$, head and neck cancer $(n=10)$, and lymphoma $(n=7)$ were evaluated. In the entire group, tumor maximum standardized uptake value and tumor-to-muscle ratio correlated significantly with $\mathrm{Ki}-67(\tau=0.27, P=0.04$, and $\tau=0.38, P=0.003$, respectively), but no significant correlation was observed between $\mathrm{Ki}-67$ and tumor-to-normal-tissue ratio $(\tau=0.07, P=0.56)$ or distribution volume ratio $(\tau=$ $0.26, P=0.14)$. On the basis of whole-body PET data, the gallbladder is the dose-limiting organ, with an average radiation dose of $0.091 \mathrm{mGy} / \mathrm{MBq}$. The whole-body and effective doses were $0.012 \mathrm{mGy} / \mathrm{MBq}$ and $0.016 \mathrm{mSv} / \mathrm{MBq}$, respectively. No adverse effects of ${ }^{18} \mathrm{~F}-\mathrm{ISO}-1$ were encountered. Conclusion: The presence of a significant correlation between ${ }^{18} \mathrm{~F}-\mathrm{ISO}-1$ and $\mathrm{Ki}-67$ makes this agent promising for evaluation of the proliferative status of solid tumors. The relatively small absorbed doses to normal organs allow for the safe administration of up to $550 \mathrm{MBq}$, which is sufficient for PET imaging in clinical trials.

Key Words: PET; cell proliferation; ${ }^{18} \mathrm{~F}-I S O-1$; cancer

J Nucl Med 2013; 54:350-357

DOI: 10.2967/jnumed.112.111948

Received Jul. 27, 2012; revision accepted Oct. 3, 2012.

For correspondence contact: Farrokh Dehdashti, Mallinckrodt Institute of

Radiology, 510 S. Kingshighway Blvd., St. Louis, MO 63110.

E-mail: dehdashtif@mir.wustl.edu

Published online Jan. 28, 2013

COPYRIGHT (C 2013 by the Society of Nuclear Medicine and Molecular Imaging, Inc.
$\mathbf{T}$ rates of tumor cell proliferation. Measurement of cell proliferation can provide useful information on the prognosis and aggressiveness of cancer and can be used to guide treatment in clinical practice (1). The ideal prognostic factors guide the choice of chemotherapy or nonstandard therapies by identifying patients who are at a higher risk of recurrence. An assessment of tumor proliferation during or after systemic therapy has the potential to be a predictor of response and allow tailoring of therapy. Additionally, information on proliferation can be used for the development of therapeutic agents, some of which may be targeted directly at specific points in the cell division pathway. Many studies suggest that cell proliferation governs tumor growth and invasiveness (2).

A PET marker of proliferation, $3^{\prime}$-deoxy- $3^{\prime}-{ }^{18} \mathrm{~F}$-fluorothymidine $\left({ }^{18} \mathrm{~F}\right.$-FLT), a radiolabeled analog of thymidine, has been used for imaging tumor proliferation rate in humans $(3,4) .{ }^{18} \mathrm{~F}$-FLT is not incorporated into DNA and is trapped inside the tumor cell after conversion to the corresponding $5^{\prime}$-phosphate by thymidine kinase 1 (TK1) $(5,6)$. Since TK1 is expressed in the $S$ phase of the cell cycle and inactivated by cyclin-dependent kinase- 1 in the early G2 phase of the cell cycle, both ${ }^{11} \mathrm{C}$-thymidine and ${ }^{18} \mathrm{~F}$-FLT provide a pulse-labeling measurement of the percentage of cells in $\mathrm{S}$ phase. Thus, an agent providing a pulse label of the S-phase fraction is capable of measuring tumor proliferation rate since a fast-growing tumor (i.e., fast tumor-doubling time) has a high S-phase fraction. However, radiolabeled thymidine analogs do not measure the proliferative status of a tumor since they cannot differentiate between proliferating (P) cells in $\mathrm{G} 1, \mathrm{G} 2$, and $\mathrm{M}$ phases versus quiescent (Q) tumor cells in G0. Therefore, ${ }^{18} \mathrm{~F}$-FLT (or any agent that measures S-phase fraction) will underestimate the proliferative status of a solid tumor, which is operationally defined as the $\mathrm{P}: \mathrm{Q}$ ratio (7). Thus, a noninvasive imaging procedure that can provide an accurate measurement of the proliferative status of a solid tumor provides an important alternative to imaging proliferation rate with PET via radiolabeled thymidine analogs. 
We have synthesized and characterized a promising ${ }^{18} \mathrm{~F}-$ labeled $\sigma 2$-receptor ligand for PET, $N$-(4-(6,7-dimethoxy-3,4-dihydroisoquinolin-2(1H)-yl)butyl)-2-(2-18 F-fluoroethoxy) -5-methylbenzamide $\left({ }^{18} \mathrm{~F}-3 \mathrm{c}\right)$, called ${ }^{18} \mathrm{~F}$-ISO- $1 .{ }^{18} \mathrm{~F}-\mathrm{ISO}-1$ exhibited the highest tumor-to-blood and tumor-to-muscle ratios in preclinical studies relative to its structural congeners $(7,8)$. Thus, we have chosen ${ }^{18} \mathrm{~F}-\mathrm{ISO}-1$ to study the feasibility of imaging patients with different cancer types including breast, head and neck, and diffuse large B-cell lymphoma with PET/CT. The aims of this first study in humans were to document the safety of ${ }^{18} \mathrm{~F}-\mathrm{ISO}-1$, to estimate human dosimetry based on PET results, and to correlate tumor ${ }^{18} \mathrm{~F}-\mathrm{ISO}-1$ uptake with tumor tissue assays of Ki-67 and mitotic index.

\section{MATERIALS AND METHODS}

\section{Patient Population}

This study was conducted under the aegis of investigational new drug application 102941 submitted to the U.S. Food and Drug Administration and was approved by the Institutional Review Board and the Radioactive Drug Research Committee at Washington University School of Medicine. All patients gave written informed consent before participation. We studied 30 adult patients (14 men and 16 women) with newly diagnosed breast cancer, head and neck cancer, or lymphoma. All patients had their tumor Ki-67 and mitotic index confirmed by morphologic and immunohistochemical assessment by a pathologist (9). Patients were required to have a lesion size of at least $1.5 \mathrm{~cm}$ as determined by imaging studies (mammography, ultrasonography, CT, or MR imaging) or physical examination. All patients underwent routine clinical staging as dictated by the treating medical oncologist or surgeon.

\section{${ }^{18} \mathrm{~F}-$ ISO-1 Radiopharmaceutical Synthesis}

${ }^{18} \mathrm{~F}-\mathrm{ISO}-1$ was produced from the ISO-1-mesylate, by treatment with Kryptofix 222 (Merck) and in accordance with the modified published procedure (8). Production was performed either on a robotic automated system (Catalyst-5 Robot; Thermo CRS Ltd.) or on an E-Z Modular Lab System (Eckert \& Ziegler Eurotope $\mathrm{GmbH})$.

\section{PET Procedure}

For safety evaluation, all patients underwent vital-sign measurement, clinical laboratory testing, and electrocardiography before ${ }^{18}$ F-ISO-1 administration, as well as during and after the completion of imaging.

${ }^{18} \mathrm{~F}-\mathrm{ISO}-1$ PET was performed before initiation of standardof-care therapy. PET was performed with a Biograph 40 TP/TV PET/CT scanner (Siemens). Each patient received approximately $296 \mathrm{MBq}(8 \mathrm{mCi})$ of ${ }^{18} \mathrm{~F}-\mathrm{ISO}-1$ intravenously over a period of $60 \mathrm{~s}$.

Twelve patients underwent whole-body ${ }^{18} \mathrm{~F}-\mathrm{ISO}-1 \mathrm{PET}$ at 2 separate time points to provide data for human dosimetry calculation. Patients were imaged at 0 and $120 \mathrm{~min}, 30$ and $150 \mathrm{~min}, 60$ and $180 \mathrm{~min}$, or 90 and $210 \mathrm{~min}$ after injection. For imaging, the subjects were placed supine on the imaging table with arms resting above the head, if possible. A spiral CT scan for attenuation correction was obtained from the top of the skull through the upper thighs. The spiral CT was performed at a maximum of 50 effective milliampere-seconds (using CARE Dose; Siemens) and $120 \mathrm{kVp}$. Immediately after the attenuation CT scan, emission images beginning at the pelvis and proceeding through the top of the skull were obtained (1-5 min per bed position). The exact timing was dependent on the size of the patient and the injected dose.

The remaining 18 subjects with breast cancer $(n=6)$, head and neck cancer $(n=4)$, or lymphoma $(n=4)$ underwent $60 \mathrm{~min}$ of dynamic imaging for kinetic modeling at the level of the tumor (and heart, when in the field of view). This imaging session consisted of CT for attenuation correction and 60 min of dynamic imaging to coincide with ${ }^{18} \mathrm{~F}-\mathrm{ISO}-1$ injection (reframing rate: $30 \times$ $2 \mathrm{~s}, 12 \times 10 \mathrm{~s}, 6 \times 20 \mathrm{~s}, 10 \times 60 \mathrm{~s}$, and $9 \times 300 \mathrm{~s}$ ). Approximately 90 and 120 min after the injection of ${ }^{18} \mathrm{~F}-\mathrm{ISO}-1$, additional static images (5-min emission with CT for attenuation correction) were obtained at the level of the tumor. Time-activity curves were generated from the dynamic data to determine the optimal time for static imaging.

Blood samples from 2 patients ( $1 \mathrm{~mL}$ of whole blood) were used for measurement of the free fraction of the radiotracer and metabolite analysis using high-performance liquid chromatography.

\section{Image Analysis}

For qualitative analysis, the ${ }^{18} \mathrm{~F}-\mathrm{ISO}-1$ uptake of each tumor was compared with that of the corresponding site in the normal comparable tissue according to the following grading scale: no uptake (tumor $\leq$ background), minimal uptake (tumor $=$ background), moderate uptake (tumor $>$ background), and intense uptake (tumor $>>$ background). In addition, the images were evaluated semiquantitatively by measurement of the tumor maximum standardized uptake value $\left(\mathrm{SUV}_{\max }\right)$ and the tumor-tonormal-tissue $(\mathrm{T} / \mathrm{N})$ and tumor-to-muscle $(\mathrm{T} / \mathrm{M})$ activity ratios. Regions of interest (ROIs) were drawn around the entire lesion with knowledge of the location of the tumor. In addition, similar ROIs were drawn on contralateral normal tissue and an approximately $1.5 \times 1.5 \mathrm{~cm}$ ROI was drawn on muscle. The T/N ratio was calculated by dividing the $\mathrm{SUV}_{\max }$ of tumor by the $\mathrm{SUV}_{\max }$ of normal tissue. The T/M ratio was calculated by dividing the $\mathrm{SUV}_{\max }$ of tumor by the mean standardized uptake value of muscle.

Preliminary analysis of small-animal PET images suggested that ${ }^{18} \mathrm{~F}-\mathrm{ISO}-1$ displays classic receptor-ligand kinetics in target tumor tissue (Shoghi et al., unpublished data, December 2012). In the absence of free-fraction-corrected ${ }^{18} \mathrm{~F}-\mathrm{ISO}-1$ input function, we performed classic Logan graphical analyses $(10,11)$ with a reference tissue as input to ascertain the relative distribution volume ratio (DVR) between target (tumor) ROI and reference ROI. The DVR was determined by estimating the slope of the linear portion of the Logan plot, typically using the last 5 data points. The reference ROIs were muscles and normal surrounding tissues or a similar contralateral organ.

\section{Image-Derived Patient Dosimetry}

Organ activity data were obtained by drawing ROIs on the PET images for the following organs: liver, spleen, pancreas, lung, kidneys, brain, heart, gallbladder, small intestines, and urinary bladder. The fused PET/CT images of all patients were used to guide the delineation of the ROIs. The ROIs on the liver and small intestines were drawn over several adjacent slices to encompass most of the visible part of the corresponding organs on the PET images. For these organs, the average activity concentration was determined, and the total amount of activity was calculated by multiplying this value by the organ mass for 
a standard adult man and then scaling this value by the patient's mass relative to the standard model. The total activity in each organ was divided by the injected activity to derive the percentage injected dose for each organ at each time point. For the gallbladder and urinary bladder, the total activity was measured using a large ROI encompassing the whole organ as visible on the images. Time-activity curves were then obtained by combining the data from all patients, decay-corrected to the injection time. Finally, organ residence times were calculated by analytic integration of a clearance or uptake function fitted as a combination of exponential functions. All unmeasured activity was assigned to the remainder of the body. The measured residence times were used in OLINDA/EXM to yield the human radiation dose estimates using the standard adult male model. The cumulative activity contained in the urinary bladder, as visible on the images, was used to evaluate the amount of excreted activity via the urinary track using the bladder model in OLINDA.

\section{In Vitro Analysis of Tumor Tissue}

The tissues were routinely fixed in $10 \%$ buffered formalin, embedded in paraffin, and serially sectioned into 4- $\mu \mathrm{m}$-thick slices for routine hematoxylin and eosin staining to assess the mitotic figures.

Ki-67 immunohistochemistry (Ventana Medical Systems, clone 30-9, predilute) was performed using an autostainer (Benchmark XT System; Ventana Medical Systems) according to the manufacturer's instructions. Positive and negative controls were run simultaneously.

Sections were examined and mitotic figures were counted in 10 high-power fields $(\times 1,000)$ (BX40; Olympus) selected in the proliferatively active periphery of the tumor, when possible, and the mean number of mitotic figures reported. The mitotic index was assessed by Ki-67 staining and semiquantitated by providing the mean percentage of staining tumor cells in 3 high-power fields $(\times 1,000)(\mathrm{BX} 40)$ in areas of greatest staining density.

\section{Statistical Analysis}

Means and SDs of Ki-67, mitotic index, and ${ }^{18} \mathrm{~F}-\mathrm{ISO}-1$ uptake measures $\left(\mathrm{SUV}_{\max }, \mathrm{T} / \mathrm{N}\right.$, and $\left.\mathrm{T} / \mathrm{M}\right)$ were calculated. The correlation between Ki-67, mitotic index, and the PET uptake measures was described by the Kendall $\tau$-coefficient, which measures the degree of similarity between 2 variables based on their relative rankings rather than the exact values. The distributions of the ${ }^{18} \mathrm{~F}-\mathrm{ISO}-1$ uptake measures between tumors with high versus low Ki-67 were also compared using the Mann-Whitney rank-sum test, and receiver operating characteristics were used to determine the best cutoff to distinguish tumors with high Ki-67 from those with low Ki-67.

\section{RESULTS}

\section{Patient Characteristics}

Thirty patients were enrolled in the study. The demographic characteristics of the patients are summarized in Table 1. Their mean age was 55.3 y (range, 38-80 y). There were 13 patients with primary breast cancer (14 primary cancers), 10 with primary head and neck cancer, and 7 with lymphoma (diffuse large B-cell lymphoma).

\section{Safety Evaluation}

The mean and SD of the administered mass of ${ }^{18} \mathrm{~F}$-ISO-1 was $2.1 \pm 0.97 \mu \mathrm{g}$ (range, 0.89-4.3 $\mu \mathrm{g}$ ). The mean ad- ministered activity was $282.9 \pm 45.7 \mathrm{MBq}$ (range, 99.2299.7 MBq). There were no adverse or clinically detectable pharmacologic effects in any of the 30 patients. No significant changes in vital signs or in the results of laboratory studies or electrocardiograms were observed.

\section{PET Results}

Thirty-one tumors were evaluated. One patient had 2 foci of breast cancer. Uptake in the tumor mass was markedly increased relative to normal comparable tissue in 2 tumors, moderately increased in 15 , and mild to minimally increased in the remaining 14. Examples of tumor uptake of ${ }^{18} \mathrm{~F}$-ISO-1 are shown in Figure 1. Based on receiver-operating-characteristic analysis, a $\mathrm{Ki}-67$ of $35 \%$ was the best cutoff to distinguish between the tumors with high Ki-67 $(>35 \%)$ and low Ki-67 ( $<35 \%$ ) (Fig. 2, top). On the basis of qualitative analysis, moderately or markedly increased uptake was seen in $65 \%(11 / 17)$ of tumors with high $\mathrm{Ki}-67$ versus $43 \%(6 / 14)$ of those with low Ki-67. Tumor ${ }^{18} \mathrm{~F}-\mathrm{ISO}-1$ uptake assessed by T/M was significantly different in highand low-Ki-67 groups (mean $\pm \mathrm{SD}, 4.9 \pm 3.1$ vs. $2.6 \pm 0.8$, $P=0.0007)$. However, no significant difference was noted between high- or low-Ki-67 groups and tumor ${ }^{18} \mathrm{~F}-\mathrm{ISO}-1$ uptake assessed by $\mathrm{SUV}_{\max }$, T/N ratio, and DVR.

The number of patients in each disease group was too small to allow for a reliable assessment between the tumor ${ }^{18} \mathrm{~F}-\mathrm{ISO}-1, \mathrm{Ki}-67$, and mitotic index. In the entire group, there was a significant correlation between tumor Ki-67 and ${ }^{18} \mathrm{~F}$-ISO-1 uptake, assessed by T/M and $\mathrm{SUV}_{\max }(\tau=0.27$, $P=0.04$, and $\tau=0.38, P=0.003$, respectively) (Fig. 2, bottom). However, there was no significant correlation between Ki-67 and tumor ${ }^{18} \mathrm{~F}-\mathrm{ISO}-1$ uptake assessed by T/N ( $\tau=0.07, P=0.56)$ or by DVR $(\tau=0.26, P=0.14)$ in the dynamic group. There was no significant correlation between mitotic index and tumor ${ }^{18} \mathrm{~F}$-ISO-1 uptake, as measured by T/M, SUV $\max$, T/N, and DVR $(P=0.17,0.5,0.15$, and 0.7 , respectively).

The analysis of the dynamic imaging $(n=18)$ indicated that tumor uptake peaked a few minutes after injection and did not significantly change throughout the $60 \mathrm{~min}$ of dynamic imaging. Similarly, activity in the blood (measured from an ROI over the left ventricular chamber) showed rapid clearance to approximately $0.004 \% \mathrm{ID} / \mathrm{mL}$ by approximately $5 \mathrm{~min}$ (Fig. 3). In breast cancer patients for whom the heart was in the field of view, blood-pool activity was higher than tumor uptake. Blood activity was fitted with a biexponential clearance model and was seen to rapidly wash out, with a biologic half-life of $12 \mathrm{~s}$, and then reach a much slower clearance with a half-life of $138 \mathrm{~min}$. Assuming an $8 \%$ blood volume per body weight, this finding indicates that $20 \%-$ $25 \%$ of the activity was still circulating in the blood. Freefraction measurement indicated that ${ }^{18} \mathrm{~F}$-ISO-1 bound tightly to plasma proteins, having a free fraction of only $1 \%$. Metabolite analysis indicated that the form of radioactivity present in blood was approximately $90 \%$ parent compound, ${ }^{18} \mathrm{~F}-\mathrm{ISO}-1$, with the remaining $10 \%$ being localized 
TABLE 1

Patient Demographic Data

\begin{tabular}{|c|c|c|c|c|c|c|c|c|c|c|c|}
\hline Patient & $\begin{array}{l}\text { Age } \\
\text { (y) }\end{array}$ & $\begin{array}{l}\text { Injected } \\
\text { dose } \\
(\mathrm{MBq})\end{array}$ & $\begin{array}{c}\text { Tracer } \\
\text { mass } \\
(\mu g)\end{array}$ & $\begin{array}{l}\text { Cancer } \\
\text { type }\end{array}$ & $\begin{array}{c}\mathrm{Ki}-67 \\
(\%)\end{array}$ & $\begin{array}{l}\text { Mitotic } \\
\text { index }\end{array}$ & $\begin{array}{l}\text { Visual } \\
\text { score }\end{array}$ & $\mathrm{T} / \mathrm{N}$ & SUV & DVR & $\mathrm{T} / \mathrm{M}$ \\
\hline \multicolumn{12}{|l|}{$\begin{array}{l}\text { Dynamic } \\
\text { patients }\end{array}$} \\
\hline 1 & 63 & 133.2 & 1.23 & $H \& N$ & 97 & 7.2 & ++ & 2.3 & 4.0 & 1.3 & 4.1 \\
\hline 2 & 46 & 299.7 & 1.29 & Breast & 40 & 4.3 & ++ & 0.9 & 1.3 & 1.6 & 2.8 \\
\hline 3 & 50 & 296 & 0.95 & $\mathrm{H} \& \mathrm{~N}$ & 4 & 3.4 & + & 1.1 & 2.0 & 1.0 & 1.9 \\
\hline 4 & 64 & 296 & NA & $H \& N$ & 30 & 2.3 & + & 1.1 & 3.5 & 1.2 & 2.3 \\
\hline 5 & 47 & 296 & 2.31 & Breast & 7 & 0.4 & ++ & 3.9 & 3.5 & 3.3 & 4.4 \\
\hline 6 & 80 & 296 & NA & Lymph & 12 & 0.0 & ++ & 2.4 & 4.3 & 2.7 & 3.3 \\
\hline 7 & 38 & 292.3 & 1.15 & Breast & 40 & 1.2 & + & 1.8 & 3.1 & 2.2 & 3.4 \\
\hline 8 & 42 & 284.9 & 1.61 & Breast & 53 & 5 & + & 1.6 & 3.4 & 2.2 & 6.8 \\
\hline 9 & 46 & 296 & 2.29 & Lymph & 37 & 1 & ++ & 2.5 & 3.8 & 2.5 & 6.3 \\
\hline \multirow[t]{2}{*}{10} & 45 & 296 & 2.65 & Breast1 & $<5$ & 0.5 & ++ & 1.2 & 2.0 & 1.3 & 2.0 \\
\hline & & & & Breast2 & 22 & 0.6 & ++ & 1.5 & 2.4 & 1.4 & 2.4 \\
\hline 11 & 68 & 296 & 2.76 & Lymph & 37 & 0.7 & ++ & 1.7 & 2.8 & 2.1 & 3.5 \\
\hline 12 & 76 & 296 & 1.86 & Lymph & 63 & Necrotic & +++ & 5.0 & 11.1 & 2.7 & 11.1 \\
\hline 13 & 67 & 292.3 & 1.62 & Breast & 23 & 1.2 & + & 1.2 & 2.0 & 1.4 & 2.8 \\
\hline 14 & 41 & 296 & 4.30 & Breast & $<5$ & 0 & + & 1.3 & 1.9 & 1.2 & 3.2 \\
\hline 15 & 56 & 296 & 2.10 & Breast & 8 & 0.3 & + & 1.2 & 1.4 & 1.7 & 2.0 \\
\hline 16 & 55 & 296 & 3.94 & Breast & 7.3 & 0.3 & + & 1.9 & 1.7 & 1.3 & 2.1 \\
\hline 17 & 50 & 292.3 & 2.05 & Breast & 5 & 0.1 & ++ & 2.1 & 2.3 & 1.2 & 2.8 \\
\hline 18 & 60 & 292.3 & NAv & Breast & 5.3 & 0.4 & ++ & 2.9 & 2.3 & 2.4 & 2.1 \\
\hline \multicolumn{12}{|l|}{$\begin{array}{l}\text { Dosimetry } \\
\text { patients }\end{array}$} \\
\hline 1 & 53 & 99 & 0.99 & Lymph & 87 & 11.1 & ++ & 2.8 & 5.1 & NA & 3.8 \\
\hline 2 & 64 & 296 & 0.85 & $H \& N$ & 63 & 5.0 & + & 1.3 & 3.1 & NA & 2.7 \\
\hline 3 & 52 & 296 & 1.93 & $\mathrm{H} \& \mathrm{~N}$ & 87 & 13.1 & ++ & 1.1 & 1.9 & NA & 3.2 \\
\hline 4 & 51 & 296 & 2.12 & Breast & 70 & 4.0 & + & 1.2 & 1.9 & NA & 3.0 \\
\hline 5 & 70 & 296 & NAv & $H \& N$ & 80 & 10.3 & ++ & 1.4 & 3.0 & NA & 4.3 \\
\hline 6 & 42 & 296 & 2.90 & Lymph & 67 & 3.5 & ++ & 4.5 & 3.3 & NA & 4.5 \\
\hline 7 & 60 & 303 & 1.59 & $H \& N$ & 37 & 2.2 & + & 1.2 & 2.0 & $\mathrm{NA}$ & 4.0 \\
\hline 8 & 70 & 296 & 4.30 & $H \& N$ & 73 & 2.4 & ++ & 2.0 & 2.9 & NA & 2.9 \\
\hline 9 & 50 & 292 & 1.45 & $H \& N$ & 33 & 3 & + & 1.1 & 2.0 & NA & 4.0 \\
\hline 10 & 52 & 285 & NAv & Lymph & 47 & 1 & +++ & 2.3 & 8.4 & NA & 14.0 \\
\hline 11 & 31 & 292 & 2.80 & $H \& N$ & 47 & 1 & + & 1.3 & 2.3 & NA & 3.8 \\
\hline 12 & 69 & 296 & 2.18 & Breast & 20 & 1.8 & + & 1.5 & 1.4 & NA & 1.7 \\
\hline
\end{tabular}

$+=$ minimal uptake; $++=$ moderate uptake; $+++=$ marked uptake; $\mathrm{H} \& \mathrm{~N}=$ head and neck; lymph $=$ lymphoma; $\mathrm{NA}=$ not applicable; NAv = not available.

in red blood cells. The tumor had already been seen to reach a stable value of activity at 10-20 min after injection.

\section{Whole-Body PET Dosimetry Results}

The $\mathrm{SUV}_{\max }$ data in normal organs over the course of the imaging sessions were as follows: liver, $8.4 \pm 2.5$; lungs, $1.8 \pm 1.2$; kidneys, $2.2 \pm 0.8$; brain, $0.3 \pm 0.1$; heart wall, $2.8 \pm 0.7$; spleen, $2.0 \pm 0.7$; pancreas, $11.5 \pm$ 5.3; small intestine, $3.2 \pm 1.3$; and gallbladder, $16.7 \pm$ 8.7. Typical whole-body images of the tracer distribution (Fig. 4) showed dominant activity in the liver, gallbladder, and pancreas at $30 \mathrm{~min}$. The average accumulation over the 3.5-h imaging period was highest in the gallbladder, pancreas, and liver. The measured organ time-activity curves are presented in the supplemental data (available online at http://jnm.snmjournals.org), and the corresponding residence times are listed in Table 2. The longest residence times were in the liver and gallbladder. Gallbladder uptake was seen to increase linearly with time at a rate of $0.17 \%$ per hour. The gallbladder time-activity curve was integrated until $6 \mathrm{~h}$ after injection with the assumption that this organ empties at this time. Within the time of imaging, the small intestine contained approximately $2 \%$ of the injected activity. Radiation doses are listed in Table 3. The highest doses were 0.091, 0.070, and $0.054 \mathrm{mGy} / \mathrm{MBq}$ to the gallbladder, liver, and pancreas, respectively. The whole-body dose was $0.012 \mathrm{mGy} / \mathrm{MBq}$, and the effective dose was $0.016 \mathrm{mSv} / \mathrm{MBq}$. Under the guidelines of $50 \mathrm{mGy}$ for the highest dose to any organ, a maximum of $550 \mathrm{MBq}$ can be injected and will yield an effective dose of $8.6 \mathrm{mSv}$. This amount is commensurate with ${ }^{18}$ F-FDG and therefore allows for safe and efficient imaging of patients. Overall, $31 \%$ of the injected activity was measured in the visible organs. The excreted amount 


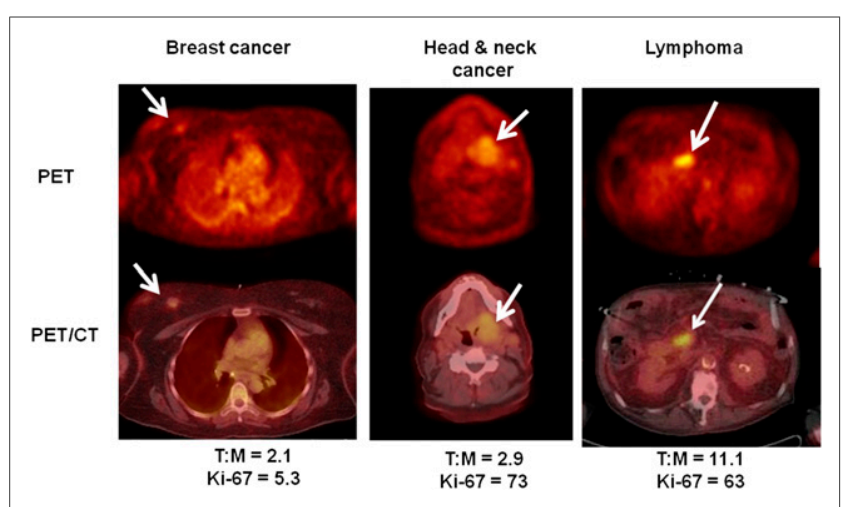

FIGURE 1. Transaxial ${ }^{18} \mathrm{~F}-$ ISO PET and PET/CT image of patient with breast cancer (left), head and neck cancer (middle), and lymphoma (right) showing different degrees of uptake in their tumors (arrows).

derived from the OLINDA bladder model was $1 \%$ of the total activity.

\section{DISCUSSION}

One of the hallmarks of cancer is cellular proliferation, which is an important prognostic indicator of tumor behavior and a crucial factor to monitoring the effectiveness of anticancer therapy. Tumors with a high cell-proliferation status may be at a higher risk of recurrence and may benefit from therapies tailored to the individual patient. Many anticancer therapies target cycling cancer cells and are ineffective to Q or "dormant" cancer cells. Monitoring of cell proliferation during therapy can be used to assess the effectiveness of therapy and may allow for further tailoring of therapy. Ki-67, a marker of cell proliferation that is expressed in all phases (S, G1, G2, and M) of the cell cycle, is not expressed in Q (G0) cancer cells. A linear relationship has been demonstrated between the Ki-67 index and the S-phase fraction of cells (12). Currently, determination of Ki-67 from a biopsy specimen or surgical resection of the tumor is the accepted method for assessment of cell proliferation. However, this method is invasive and not all tumors are readily accessible for tissue sampling or surgical resection.

PET imaging of cell proliferation has shown promise as an alternative method and is considered an important tool for assessment of the effectiveness of cancer therapies. Several radiopharmaceuticals have been proposed for PET imaging of cell proliferation, with the most promising to date being ${ }^{18} \mathrm{~F}$-FLT. ${ }^{18} \mathrm{~F}$-FLT is a thymidine analog and, once inside the cell, is phosphorylated by TK1 into FLT monophosphate, which is trapped within the cell. TK1 is the rate-limiting enzyme in the salvage pathway of DNA synthesis and exhibits catalytic activity primarily during the $\mathrm{S}$ phase of the cell cycle, and PET studies with ${ }^{18} \mathrm{~F}-$ FLT therefore reflect a pulse label of the S-phase fraction of cycling cancer cells $(13,14)$. Thus, a positive correlation between tumor ${ }^{18} \mathrm{~F}$-FLT uptake and in vitro analysis of Ki-67 expression should be expected on the basis of published reports demonstrating the linear relationship between S-phase fraction and Ki-67 expression. However, there are conflicting results in the correlation of tumor ${ }^{18} \mathrm{~F}-$ FLT uptake and Ki-67, and although some reports demonstrated a strong correlation between ${ }^{18} \mathrm{~F}$-FLT uptake and Ki-67 expression (15-18), others have demonstrated the lack of such correlation $(19,20)$. One of the reasons for this discrepancy is the loss of cell cycle-specific regulation of TK1 in cancer cells (21). Another reason could be related to the fact that ${ }^{18} \mathrm{~F}$-FLT PET measures cell proliferation of the entire tumor whereas biopsy samples for the assessment of $\mathrm{Ki}-67$ measure proliferation in only a small part of the tumor. Furthermore, ${ }^{18}$ F-FLT has additional limitations such as high bone marrow activity and low tumor uptake in comparison to ${ }^{18} \mathrm{~F}-\mathrm{FDG}$, resulting in lower sensitivity in the detection of nodal and distant metastatic disease (22).

Over the past decade, a limited number of studies have been reported using PET- and SPECT-based radiotracers for imaging $\sigma$-receptors $(23,24)$. However, these tracers either were $\sigma 1$-selective or bound with a similar affinity to $\sigma 1$ - and $\sigma 2$-receptors. There is, however, no evidence

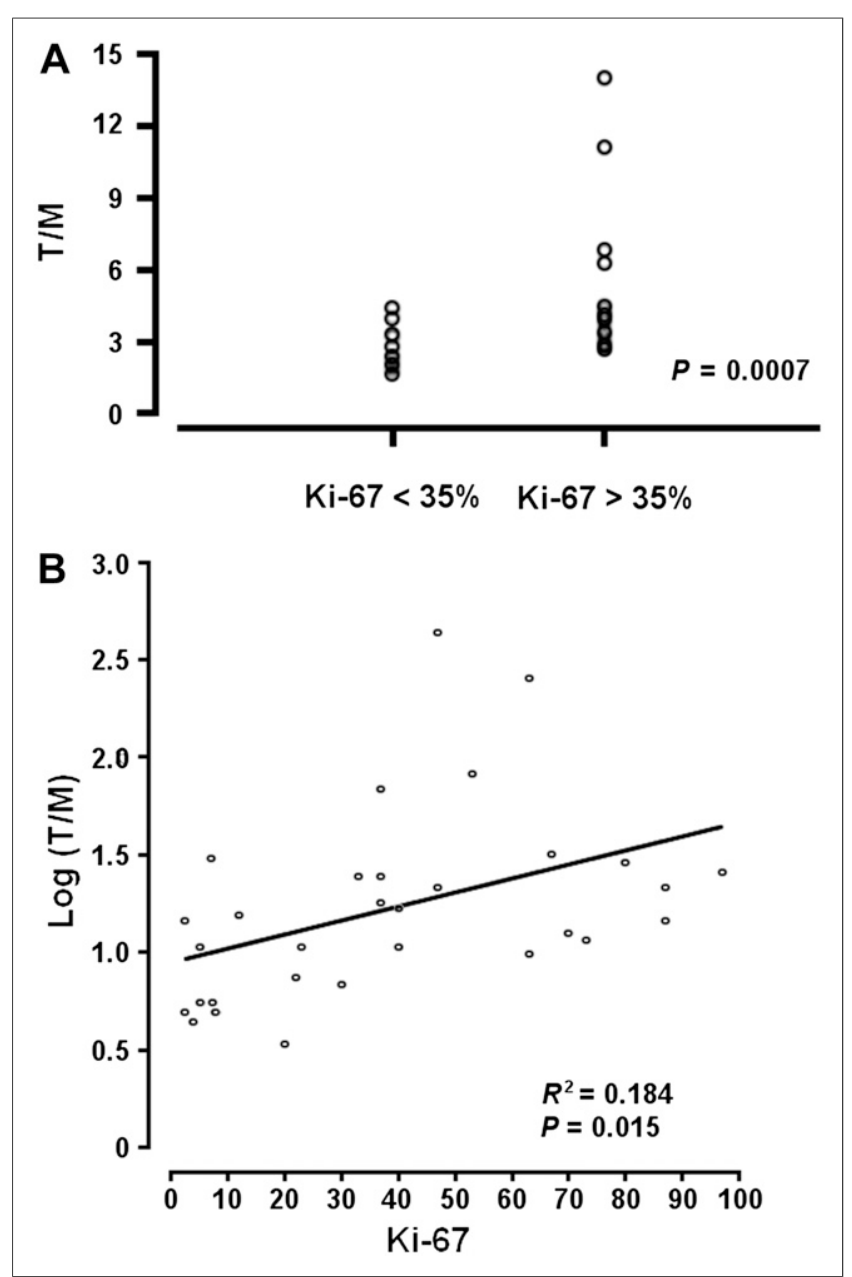

FIGURE 2. Correlation of ${ }^{18} \mathrm{~F}-I S O-1$, as expressed by T/M, with low $(<35 \%)$ and high ( $>35 \%$ ) expression of Ki-67 (top), and correlation of $\mathrm{Ki}-67$ with ${ }^{18} \mathrm{~F}-\mathrm{ISO}-1$ expressed by T/M (bottom) 


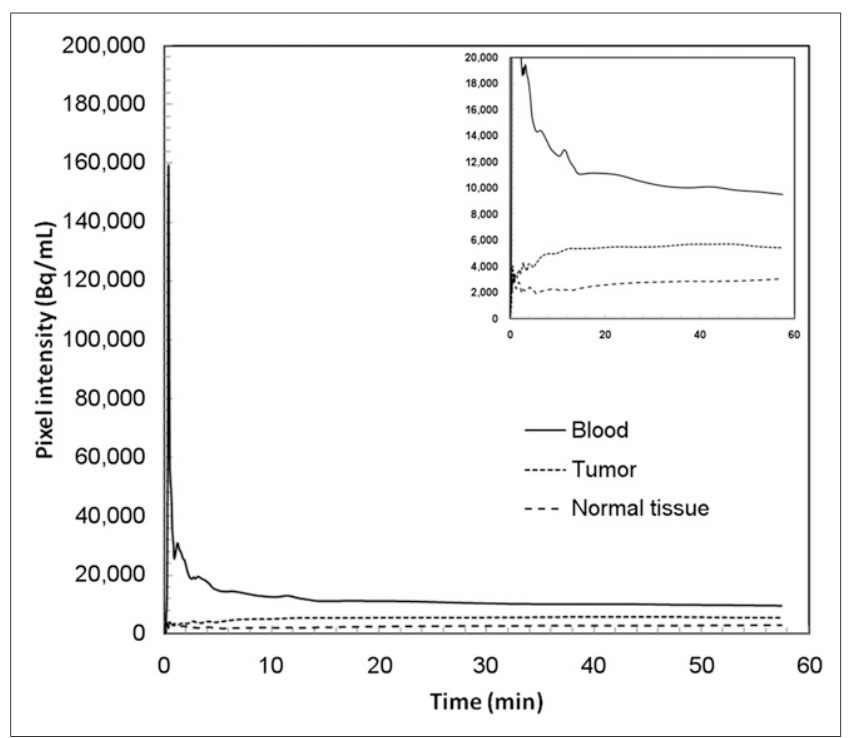

FIGURE 3. Time-activity curve of ${ }^{18} \mathrm{~F}-$ ISO-1 activity, as expressed by $\mathrm{Bq} / \mathrm{mL}$ in blood (taken from left ventricle), breast tumor, and contralateral normal breast tissue. Inset shows constant ratios of activities reached 20 min after injection.

supporting the use of the $\sigma 1$-receptor as a biomarker for imaging the proliferative status (i.e., $\mathrm{P}: \mathrm{Q}$ ratio) of solid tumors. On the other hand, the $\sigma 2$-receptor has been fully validated as a biomarker for imaging the proliferative status of solid tumors, and the results of the current study demonstrate that ${ }^{18} \mathrm{~F}$-ISO-1 has the potential to provide this information in cancer patients. Furthermore, our group has previously reported that $\sigma 2$-selective radiotracers provide a higher tumor-to-background ratio than nonselective $\sigma 1 / \sigma 2$-radiotracers in an animal model of breast cancer (25). Therefore, ${ }^{18} \mathrm{~F}$-labeled $\sigma 2$-selective PET radiotracers such as ${ }^{18} \mathrm{~F}-\mathrm{ISO}-1$ are expected to provide a higher tumor-to-background ratio in clinical imaging studies than nonselective $\sigma 1 / \sigma 2$ radiotracers.

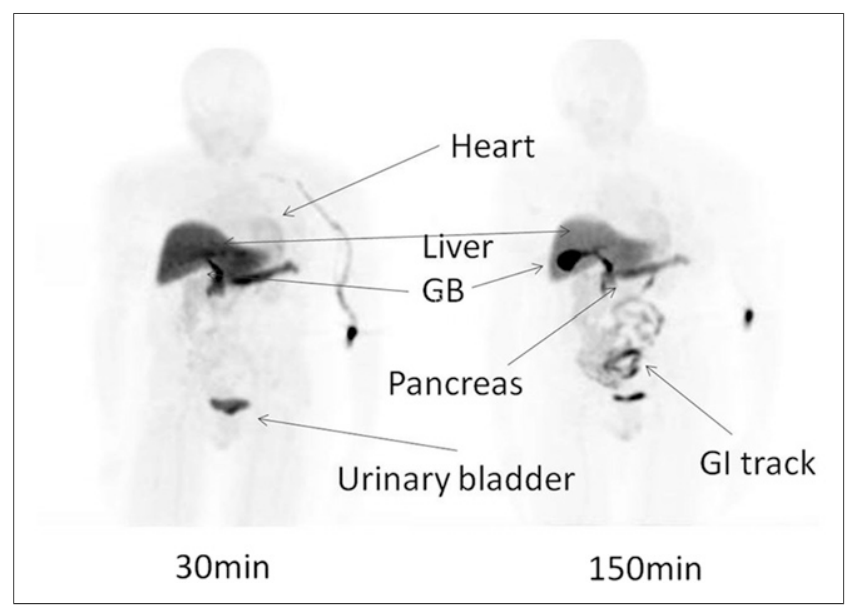

FIGURE 4. Representative coronal image of normal biodistribution of ${ }^{18} \mathrm{~F}-$ ISO-1 in dosimetry patient 5 at 30 and 150 min after injection. Infiltration of dose at site of injection in patient's left arm is seen. GB = gallbladder; $\mathrm{Gl}=$ gastrointestinal.
TABLE 2

Organ Residence Times from Human Whole-Body PET Images

\begin{tabular}{lc}
\hline \multicolumn{1}{c}{ Organ } & Time $(\mathrm{min})$ \\
\hline Liver & 31.5 \\
\hline Lungs & 3.34 \\
Kidneys & 1.42 \\
\hline Brain & 0.88 \\
Heart wall & 1.71 \\
Spleen & 0.70 \\
Pancreas & 1.37 \\
Gallbladder & 2.72 \\
Urinary bladder & 1.12 \\
\hline Remainder of body & 108.4 \\
\hline
\end{tabular}

A potential alternate to ${ }^{18} \mathrm{~F}$-FLT is ${ }^{18} \mathrm{~F}$-ISO-1, a $\sigma 2$-receptor ligand, which evaluates a completely different aspect of cellular proliferation: the proliferative status. $\sigma 2$-receptors, a marker of proliferation, are overexpressed in a variety of human cancers (such as breast cancer, small cell lung cancer, and gliomas) and rodent models of human cancer (26-28) and likely play an important role in cancer biology (29). The density of $\sigma 2$-receptors in breast tumor $\mathrm{P}$ cells is much higher than that in breast tumor Q cells (30). $\sigma 2$-receptors are upregulated during the transition from $\mathrm{Q}$ to $\mathrm{P}$ cells and are downregulated during the transition from $\mathrm{P}$ to $\mathrm{Q}$ cells. These data indicate that the $\sigma 2$-receptor is a biomarker for measuring the transition of tumor cells between proliferative

TABLE 3

Organ Radiation Doses from Human Whole-Body PET Images

\begin{tabular}{|lc}
\hline \multicolumn{1}{c}{ Organ } & Dose $(\mathrm{mGy} / \mathrm{MBq})$ \\
\hline Adrenals & 0.017 \\
\hline Brain & 0.005 \\
\hline Breast & 0.009 \\
\hline Gallbladder & 0.091 \\
\hline Lower large intestine wall & 0.012 \\
\hline Small intestine wall & 0.026 \\
\hline Stomach wall & 0.014 \\
\hline Upper large intestine wall & 0.016 \\
\hline Heart wall & 0.025 \\
\hline Kidneys & 0.024 \\
\hline Liver & 0.070 \\
\hline Lungs & 0.018 \\
\hline Muscle & 0.010 \\
\hline Ovaries & 0.013 \\
\hline Pancreas & 0.054 \\
\hline Red marrow & 0.010 \\
\hline Osteogenic cells & 0.015 \\
\hline Skin & 0.008 \\
\hline Spleen & 0.020 \\
\hline Testes & 0.009 \\
\hline Thymus & 0.011 \\
\hline Thyroid & 0.009 \\
\hline Urinary bladder wall & 0.020 \\
\hline Uterus & 0.013 \\
\hline Total body & 0.012 \\
\hline Effective dose (mSv/mBq) & 0.016 \\
\hline
\end{tabular}


and quiescent states. Tumor quiescence occurs when a solid tumor outgrows its blood supply, resulting in nutrient deprivation in regions of the tumor. The tumor cells then enter the Q state until the tumor microenvironment is optimal to sustain growth. Cells in the Q state stay undifferentiated and sometimes may remain in this state for prolonged periods. Since many chemotherapeutics target cycling (P) tumor cells and are ineffective against $Q$ tumor cells, a knowledge of the $\mathrm{P}: \mathrm{Q}$ ratio of a solid tumor should predict the likelihood that the tumor will respond to cell-cycle-specific chemotherapeutics. Thus, ${ }^{18} \mathrm{~F}-\mathrm{ISO}-1$, which provides a measure of the ratio of $\mathrm{P}$ to $\mathrm{Q}$ cells within the tumor, should provide unique information that can be useful in cancer therapy.

Our findings suggest that ${ }^{18} \mathrm{~F}$-ISO- 1 PET is useful for evaluating tumor cellular proliferation. We found a significant correlation between Ki-67 and ${ }^{18} \mathrm{~F}-\mathrm{ISO}-1$ uptake, as measured by $\mathrm{SUV}_{\max }$ and $\mathrm{T} / \mathrm{M}$, in patients with lymphoma, breast cancer, and head and neck cancer. However, no significant correlation was noted between Ki-67 and ${ }^{18} \mathrm{~F}-\mathrm{ISO}-1$ uptake, as measured by DVR and T/N. This may be related to the variability of normal-tissue uptake, which was high in the head and neck region and low in breast tissue and created difficulty with identifying the normal comparable tissue in some patients with lymphoma.

We also found that, as assessed by T/M for ${ }^{18} \mathrm{~F}-\mathrm{ISO}-1$ uptake, a Ki-67 of $35 \%$ was the best cutoff to distinguish tumors with a high Ki-67 from tumors with a low Ki-67. The analysis of the dynamic images indicated that uptake in tumor peaked early after injection and stayed unchanged throughout the $60 \mathrm{~min}$; thus, there was no significant washout. The blood activity cleared within a few minutes to a stable fraction. Free-fraction measurements indicated that ${ }^{18} \mathrm{~F}-\mathrm{ISO}-1$ binds tightly to plasma proteins, having a free fraction of only $1 \%$. Metabolite analysis indicated that approximately $90 \%$ of the parent compound is present in blood throughout the study, with the remaining $10 \%$ being localized in the red blood cells. The stable uptake of ${ }^{18} \mathrm{~F}-\mathrm{ISO}-1$ in blood, muscle, and tumor indicates that equilibrium is achieved between these compartments rapidly (10-20 min after intravenous injection) and remains stable throughout the 60-min acquisition.

The early PET images showed rapid accumulation of activity in the liver, gallbladder, and pancreas. The larger accumulation in the pancreas was due to the increased number of $\sigma 2$-receptors in this organ, whereas accumulation in the liver and gallbladder suggested hepatobiliary metabolism and clearance. The activity in the gallbladder increased over time, with large interpatient fluctuations that were probably due to differences in diet. Some patients showed significant activity in their lungs, probably related to activity in the blood. The biodistribution data showed that activity was highest in the gallbladder, with an average radiation dose of $0.091 \mathrm{mGy} / \mathrm{MBq}$. $\mathrm{Hu}-$ man radiation doses calculated from the PET images indicated an effective dose of $0.016 \mathrm{mSv} / \mathrm{MBq}$. No adverse effects were noted.

\section{CONCLUSION}

The results of this pilot study indicated that ${ }^{18} \mathrm{~F}$-ISO- 1 is a promising radiotracer for imaging the proliferative status of solid tumors. Dosimetry estimates indicated that a maximum of $550 \mathrm{MBq}$ can be administered to patients. The heterogeneity of ${ }^{18} \mathrm{~F}$-ISO-1 uptake seen in the patient population was expected since the proliferative status of solid tumors varies highly from patient to patient. The high correlation of T/M ratios with Ki-67 scores indicates that ${ }^{18} \mathrm{~F}$-ISO-1 may provide an imaging alternative to biopsy specimens for obtaining this measurement. The observation that ${ }^{18} \mathrm{~F}-\mathrm{ISO}-1$ can stratify patients into groups of high $(\mathrm{Ki}-67>35 \%)$ and low $(\mathrm{Ki}-67<35 \%)$ proliferative status is expected to be useful in selecting patients who are likely to respond to chemotherapeutics that target cycling cancer cells. Thus, ${ }^{18} \mathrm{~F}$-ISO-1 PET is feasible and safe, although additional clinical imaging studies are clearly warranted.

\section{DISCLOSURE}

The costs of publication of this article were defrayed in part by the payment of page charges. Therefore, and solely to indicate this fact, this article is hereby marked "advertisement" in accordance with 18 USC section 1734. This work was supported by Washington University Institute of Clinical and Translational Sciences (ICTS) and Isotrace Technologies Inc. Isotrace Technologies, LLC, St. Charles, Missouri, has a licensing agreement with Washington University School of Medicine for the commercialization of ${ }^{18} \mathrm{~F}$-labeled $\sigma 2$ receptor radiotracers developed in the laboratory of R.H. Mach. R.H. Mach has no financial interest in Isotrace Technologies, nor is he a paid consultant for the company. Therefore, there are no financial conflicts of interest with the authors.

\section{REFERENCES}

1. Beresford MJ, Wilson GD, Makris A. Measuring proliferation in breast cancer: practicalities and applications. Breast Cancer Res. 2006;8:216.

2. Aguirre-Ghiso JA. Models, mechanisms and clinical evidence for cancer dormancy. Nat Rev Cancer. 2007;7:834-846.

3. Shields AF, Grierson JR, Dohmen BM, et al. Imaging proliferation in vivo with [F-18]FLT and positron emission tomography. Nat Med. 1998;4:1334-1336.

4. Mier W, Haberkorn U, Eisenhut M. $\left[{ }^{18} \mathrm{~F}\right] \mathrm{FLT}$; portrait of a proliferation marker. Eur J Nucl Med Mol Imaging. 2002;29:165-169.

5. Shields AF. PET imaging with ${ }^{18}$ F-FLT and thymidine analogs: promise and pitfalls. J Nucl Med. 2003;44:1432-1434.

6. Vallabhajosula S. ${ }^{18} \mathrm{~F}$-labeled positron emission tomographic radiopharmaceuticals in oncology: an overview of radiochemistry and mechanisms of tumor localization. Semin Nucl Med. 2007;37:400-419.

7. Mach RH, Dehdashti F, Wheeler KT. PET radiotracers for imaging the proliferative status of solid tumors. PET Clin. 2009;4:1-15.

8. Tu Z, Xu J, Jones LA, et al. Fluorine-18-labeled benzamide analogues for imaging the sigma 2 receptor status of solid tumors with positron emission tomography. J Med Chem. 2007;50:3194-3204.

9. Lehr HA, Hansen DA, Kussick S, et al. Assessment of proliferative activity in breast cancer: MIB-1 immunohistochemistry versus mitotic figure count. Hum Pathol. 1999;30:1314-1320.

10. Logan J, Fowler JS, Volkow ND, et al. Graphical analysis of reversible radioligand binding from time-activity measurements applied to $\left[\mathrm{N}-{ }^{11} \mathrm{C}\right.$-methyl]- 
(-)-cocaine PET studies in human subjects. J Cereb Blood Flow Metab. 1990;10:740-747.

11. Logan J, Fowler JS, Volkow ND, Wang GJ, Ding YS, Alexoff DL. Distribution volume ratios without blood sampling from graphical analysis of PET data. J Cereb Blood Flow Metab. 1996;16:834-840.

12. Scholzen T, Gerdes J. The Ki-67 protein: from the known and the unknown. J Cell Physiol. 2000;182:311-322.

13. Francis DL, Freeman A, Visvikis D, et al. In vivo imaging of cellular proliferation in colorectal cancer using positron emission tomography. Gut. 2003;52: 1602-1606.

14. Bading JR, Shields AF. Imaging of cell proliferation: status and prospects. J Nucl Med. 2008;49(suppl 2):64S-80S.

15. Cobben DC, Elsinga PH, Suurmeijer AJ, et al. Detection and grading of soft tissue sarcomas of the extremities with ${ }^{18} \mathrm{~F}-3^{\prime}$-fluoro-3'-deoxy-L-thymidine. Clin Cancer Res. 2004;10:1685-1690.

16. Yamamoto Y, Nishiyama Y, Ishikawa S, et al. Correlation of ${ }^{18} \mathrm{~F}$-FLT and ${ }^{18} \mathrm{~F}$ FDG uptake on PET with Ki-67 immunohistochemistry in non-small cell lung cancer. Eur J Nucl Med Mol Imaging. 2007;34:1610-1616.

17. Yap CS, Czernin J, Fishbein MC, et al. Evaluation of thoracic tumors with ${ }^{18} \mathrm{~F}$-fluorothymidine and ${ }^{18} \mathrm{~F}$-fluorodeoxyglucose-positron emission tomography. Chest. 2006;129:393-401.

18. Vesselle H, Grierson J, Muzi M, et al. In vivo validation of $3^{\prime}$ deoxy- $3^{\prime}-\left[{ }^{18} \mathrm{~F}\right]$ fluorothymidine $\left(\left[{ }^{18} \mathrm{~F}\right] \mathrm{FLT}\right)$ as a proliferation imaging tracer in humans: correlation of $\left[{ }^{18} \mathrm{~F}\right] \mathrm{FLT}$ uptake by positron emission tomography with Ki-67 immunohistochemistry and flow cytometry in human lung tumors. Clin Cancer Res. 2002;8:3315-3323.

19. Brockenbrough JS, Souquet T, Morihara JK, et al. Tumor $3^{\prime}$-deoxy- $3^{\prime}-{ }^{18}$ F-fluorothymidine $\left({ }^{18} \mathrm{~F}\right.$-FLT) uptake by PET correlates with thymidine kinase 1 expression: static and kinetic analysis of ${ }^{18} \mathrm{~F}$-FLT PET studies in lung tumors. $J$ Nucl Med. 2011;52:1181-1188.
20. Kameyama R, Yamamoto Y, Izuishi K, et al. Detection of gastric cancer using ${ }^{18}$ F-FLT PET: comparison with ${ }^{18}$ F-FDG PET. Eur J Nucl Med Mol Imaging. 2009;36:382-388.

21. Schwartz JL, Tamura Y, Jordan R, Grierson JR, Krohn KA. Monitoring tumor cell proliferation by targeting DNA synthetic processes with thymidine and thymidine analogs. J Nucl Med. 2003;44:2027-2032.

22. Dimitrakopoulou-Strauss A, Strauss LG. The role of ${ }^{18} \mathrm{~F}$-FLT in cancer imaging: does it really reflect proliferation? Eur J Nucl Med Mol Imaging. 2008;35: 523-526.

23. Caveliers V, Everaert H, John CS, Lahoutte T, Bossuyt A. Sigma receptor scintigraphy with $\mathrm{N}$-[2-(1'-piperidinyl)ethyl]-3- ${ }^{123}$ I-iodo-4-methoxybenzamide of patients with suspected primary breast cancer: first clinical results. $\mathrm{J} \mathrm{Nucl}$ Med. 2002;43:1647-1649.

24. van Waarde A, Buursma AR, Hospers GA, et al. Tumor imaging with 2 sigmareceptor ligands, ${ }^{18} \mathrm{~F}-\mathrm{FE}-\mathrm{SA} 5845$ and ${ }^{11} \mathrm{C}-\mathrm{SA} 4503$ : a feasibility study. $\mathrm{J} \mathrm{Nucl}$ Med. 2004;45:1939-1945.

25. Mach RH, Huang Y, Buchheimer N, et al. [[ $\left.{ }^{18} \mathrm{~F}\right] \mathrm{N}-\left(4^{\prime}\right.$-fluorobenzyl)-4-(3-bromophenyl) acetamide for imaging the sigma receptor status of tumors: comparison with $\left[{ }^{18}\right.$ F]FDG, and [ $\left.{ }^{125 I}\right]$ IUDR. Nucl Med Biol. 2001;28:451-458.

26. Bem WT, Thomas GE, Mamone JY, et al. Overexpression of sigma receptors in nonneural human tumors. Cancer Res. 1991;51:6558-6562.

27. Vilner BJ, Bowen WD. Sigma receptor-active neuroleptics are cytotoxic to C6 glioma cells in culture. Eur J Pharmacol. 1993;244:199-201.

28. Vilner BJ, John CS, Bowen WD. Sigma-1 and sigma-2 receptors are expressed in a wide variety of human and rodent tumor cell lines. Cancer Res. 1995;55: 408-413.

29. Aydar E, Palmer CP, Djamgoz MB. Sigma receptors and cancer: possible involvement of ion channels. Cancer Res. 2004;64:5029-5035.

30. Mach RH, Smith CR, al-Nabulsi I, Whirrett BR, Childers SR, Wheeler KT. Sigma 2 receptors as potential biomarkers of proliferation in breast cancer. Cancer Res. 1997;57:156-161. 